\title{
A multifunctional targeting probe with dual-mode imaging and photothermal therapy used in vivo
}

\author{
Xiao-Shuai Zhang ${ }^{1 \dagger}$, Yang Xuan ${ }^{1 \dagger}$, Xiao-Quan Yang ${ }^{1,3{ }^{\dagger}}$, Kai Cheng ${ }^{1}$, Ruo-Yun Zhang ${ }^{1}$, Cheng Li ${ }^{1}$, Fang Tan², \\ Yuan-Cheng Cao ${ }^{2}$, Xian-Lin Song ${ }^{1}$, Jie An ${ }^{1}$, Xiao-Lin Hou ${ }^{1}$ and Yuan-Di Zhao ${ }^{1,3^{*}}$ (]
}

\begin{abstract}
Background: $\mathrm{Ag}_{2} \mathrm{~S}$ has the characteristics of conventional quantum dot such as broad excitation spectrum, narrow emission spectrum, long fluorescence lifetime, strong anti-bleaching ability, and other optical properties. Moreover, since its fluorescence emission is located in the NIR-II region, has stronger penetrating ability for tissue. $\mathrm{Ag}_{2} \mathrm{~S}$ quantum dot has strong absorption during the visible and NIR regions, it has good photothermal and photoacoustic response under certain wavelength excitation.

Results: $200 \mathrm{~nm}$ aqueous probe $\mathrm{Ag}_{2} \mathrm{~S} @ \mathrm{DSPE}-\mathrm{PEG}_{2000}-\mathrm{FA}$ ( $\mathrm{Ag}_{2} \mathrm{~S} @ \mathrm{DP}-\mathrm{FA}$ ) with good dispersibility and stability was prepared by coating hydrophobic $\mathrm{Ag}_{2} \mathrm{~S}$ with the mixture of folic acid (FA) modified DSPE-PEG 2000 (DP) and other polymers, it was found the probe had good fluorescent, photoacoustic and photothermal responses, and a low cell cytotoxicity at $50 \mathrm{\mu g} / \mathrm{mL}$ Ag concentration. Blood biochemical analysis, liver enzyme and tissue histopathological test showed that no significant influence was observed on blood and organs within 15 days after injection of the probe. In vivo and in vitro fluorescence and photoacoustic imaging of the probe further demonstrated that the $\mathrm{Ag}_{2} \mathrm{~S} @ \mathrm{DP}-\mathrm{FA}$ probe had good active targeting ability for tumor. In vivo and in vitro photothermal therapy experiments confirmed that the probe also had good ability of killing tumor by photothermal.
\end{abstract}

Conclusions: $\mathrm{Ag}_{2} \mathrm{~S} @ D P-F A$ was a safe, integrated diagnosis and treatment probe with multi-mode imaging, photothermal therapy and active targeting ability, which had a great application prospect in the early diagnosis and treatment of tumor.

Keywords: $\mathrm{Ag}_{2} \mathrm{~S}$, Cancer active targeting, Fluorescence imaging, Photoacoustic imaging, Photothermal therapy

\section{Background}

Early diagnosis of cancer can greatly improve the survival of patients [1]. More and more imaging methods have been applied to diagnose tumor, such as electronic computed tomography $(\mathrm{CT})$, photoacoustic imaging (PAI), magnetic resonance imaging (MRI), positron emission

\footnotetext{
*Correspondence: zydi@mail.hust.edu.cn

${ }^{+}$Xiao-Shuai Zhang, Yang Xuan and Xiao-Quan Yang contributed equally to this work

${ }^{3}$ Key Laboratory of Biomedical Photonics (HUST), Ministry of Education, Huazhong University of Science and Technology, Wuhan 430074, Hubei, People's Republic of China

Full list of author information is available at the end of the article
}

computed tomography (PET), fluorescence imaging (FI) and so on.

As a molecular imaging technique, FI has the advantages of high resolution and low acquisition time, it can observe the dynamic change of tumor-related molecules in real time, so it has great application prospect in early diagnosis [2-4]. However, some endogenous substances (hemoglobin, water, bilirubin and melanin, etc.) in biological tissues have strong absorption and scattering for visible light (400-700 nm) [5], which result in the limited penetration of photon. By contrast, near-infrared (NIR) light has stronger penetrating ability because of weak tissue scattering and absorption in that region, so NIR fluorescent materials usually are used as probe for in vivo 
imaging [6]. $\mathrm{Ag}_{2} \mathrm{~S}$ is a new type of low-toxic quantum dot reported in recent years. It has the characteristics of conventional quantum dot such as broad excitation spectrum, narrow emission spectrum, long fluorescence lifetime, strong anti-bleaching ability, and other optical properties [7]. Moreover, since its fluorescence emission is located in the NIR-II region, it has stronger penetrating ability for tissue and can also eliminate the interference of biological spontaneous fluorescence, which contributes to the improvement of signal-to-noise ratio [8]. So it is a promising quantum dot for in vivo imaging.

PAI is a new kind of molecular imaging technology developed in recent years [9]. In PAI, a short pulsed laser beam is used to illuminate the biological tissue. The absorption of laser pulse energy of the tissue then induces an instantaneous temperature rise and transient thermoelastic expansion, leading to ultrasonic emissions (photoacoustic waves). Researchers can map the light absorption distribution in the tissues by measuring the photoacoustic (PA) signals [10]. PAI combines the advantages of high-contrast of optical imaging and high penetration depth of ultrasound imaging, avoids the effect of light scattering in principle, can achieve the deep tissue imaging similar to ultrasound imaging and high-contrast imaging similar to optical coherence tomography, demonstrates broad prospect for early diagnosis and efficacy monitoring $[11,12] . \mathrm{Ag}_{2} \mathrm{~S}$ quantum dot has strong absorption during the visible and NIR regions [13], it has good photoacoustic response under certain wavelength excitation, so it is also a good PAI contrast agent.

Single imaging model often cannot provide comprehensive information due to the existence of certain defects. Combining two or more imaging technologies is an inevitable trend in the development of in vivo molecular imaging technology, which is also an effective way to early diagnose and treat cancer. So multi-modal imaging technology comes into being [14-16]. FI can give the three-dimensional quantitative results of fluorescence molecules in vivo, but there are some shortcomings in obtaining structural information; PAI can provide highresolution and high-contrast tissue imaging. Therefore, combining FI and PAI is an ideal dual-mode molecular imaging method [17]. FI provides the distribution and location of trace cancer-related molecules in tissues, while PAI provides deep tissue and spatial structure information.

Thermotherapy as an effective treatment for cancer has aroused widespread attention [18-21]. Tumor thermotherapy uses the physical energy to heat, make the tumor temperature rise to the effective treatment temperature $\left(>41{ }^{\circ} \mathrm{C}\right)$ [22] and maintain a certain time. Due to different temperature tolerance comparing with normal cell, tumor cell apoptosis is achieved without damaging the normal cell. Photothermal therapy (PTT) research in the past is mainly using NIR organic dyes [23]. In recent years, studies have shown that absorption cross sections of some metal nanoparticles are 4-5 times larger than the conventional dyes [24], and have better stability and stronger anti-photobleaching, so they become the ideal choice for PTT. It is gratifying that, $\mathrm{Ag}_{2} \mathrm{~S}$ quantum dot had significant photothermal effect reported by Wu et al. in 2016 [25]. It is thought that $\mathrm{Ag}_{2} \mathrm{~S}$ quantum dot can achieve NIR fluorescence and photoacoustic dual-mode imaging, meanwhile be used to kill the tumor through photothermal [26], it achieves the purpose of diagnosis and treatment integration perfectly.

In this paper, a multi-functional folic acid (FA) modified phospholipid coating $\mathrm{Ag}_{2} \mathrm{~S}$ probe $\left(\mathrm{Ag}_{2} \mathrm{~S} @ D S P E-\right.$ $\mathrm{PEG}_{2000}$-FA) with low biotoxicity was prepared by mixing lecithin, polyoxyethylene stearate, DSPE-PEG ${ }_{2000}$ (DP) and FA modified DP (DP-FA). The design idea is that DP is a very safe amphiphilic molecule whose hydrophilic end can improve the water solubility of the nanoprobe and help the probe to escape the phagocytosis of the reticuloendothelial system and prolong the cycle time in the body [27]. However, due to its limited emulsifying ability, lecithin and polyoxyethylene stearate are required to assist. These two materials can be effectively utilized by the body and have little hemolysis effect, are safe and reliable injection emulsion surfactant. FA, as a small molecule of vitamin, can bind FA receptors which are highly expressed on the surface of some tumor cells to guide the endocytosis, while it is easily coupled with nanoparticles, free of immunogenicity and low cost. Two kinds of cells were adopted, while HeLa cells (high FA receptor expression) [28] as positive cell and A549 cells (low FA receptor expression) [29] as negative cell; two kinds of probes were also adopted, while $\mathrm{Ag}_{2} \mathrm{~S} @ \mathrm{DP}-\mathrm{FA}$ as positive probe and $\mathrm{Ag}_{2} \mathrm{~S} @ \mathrm{DP}$ as negative probe. Cross-contrast experiments were performed by fluorescence, photoacoustic and photothermal, the results confirmed that $\mathrm{Ag}_{2} \mathrm{~S} @ \mathrm{DP}-\mathrm{FA}$ probe was an integrated diagnosis and treatment probe with good safety, it had abilities of fluorescence and photoacoustic dual-mode imaging, PTT and active targeting function, had large application prospect in the early diagnosis and treatment of tumor.

\section{Methods}

\section{Materials and instrument}

Diethyldithiocarbamic acid silver salt (AgDDTC, 98\%), dodecanethiol (DT, 98\%), $n$-hexane, acetone, trichloromethane, dimethyl sulfoxide (DMSO), folic acid (FA, 97\%) and pyridine were purchased from Sinopharm Group Chemical Reagent Co., Ltd. PEG-phospholipid (DSPE-PEG ${ }_{2000}$ ), amino-PEG-phospholipid (DSPE$\mathrm{PEG}_{2000}-\mathrm{NH}_{2}$ ) were purchased from Avanti, lecithin 
(98\%), polyoxyethylene stearate were purchased from Aladdin, octadecene (ODE, 90\%) was purchased from Aldrich. All reagents were used directly without further purification.

The equipments used in the experiments included UV-2550 UV-Vis spectrophotometer (Shimadzu, Japan), Tecnai G20 U-Twin High Resolution Transmission Electron Microscope (FEI, Netherlands), Nano-ZS90 Nanometer Size Meter (Malvern, UK), Ni-E Positive Slice Scanning Microscope (Nikon, Japan), SP-4430 Dry Biochemical Analyzer (Arkary, Japan), Centrifugal Concentrator (Ependorf, Germany), Elx-808 Microplate Reader (Biotek, USA), CA-700 Automatic Blood Analyzer (STAC, China), MDL-III-808-2.5 W Laser (Changchun New Industries Optoelectronics Tech. CO., LTD., China), EasIR-9 Thermal Imager (Wuhan Guide Infrared Co., LTD, China), IX71 Fluorescence Microscope (Olympus, Japan). Near infrared FI system [30] and PAI system [31, 32] were homemade by the laboratory.

\section{Synthesis of hydrophobic $\mathrm{Ag}_{2} \mathrm{~S}$}

The synthesis of $\mathrm{Ag}_{2} \mathrm{~S}$ was according to the reported method [33, 34] with slightly modified. $76.8 \mathrm{mg}$ AgDDTC, $30 \mathrm{~g}$ ODE and $6 \mathrm{~g}$ DT were added into a $100 \mathrm{~mL}$ four-necked flask and vigorously stirred with passing through $\mathrm{Ar}$, heated to $100{ }^{\circ} \mathrm{C}$ and kept for $5 \mathrm{~min}$ to remove the water then raised the temperature to $160{ }^{\circ} \mathrm{C}$, after the solution color was completely dark, kept for $10 \mathrm{~min}$ and cooled down to room temperature, after centrifugal purification for $12,000 \mathrm{r} / \mathrm{min}$ by adding acetone, the resulting $\mathrm{Ag}_{2} \mathrm{~S}$ was dissolved in chloroform and stored at $4{ }^{\circ} \mathrm{C}$. Different concentrations of $\mathrm{Ag}_{2} \mathrm{~S}$ were placed in centrifuge tubes and imaged by homemade NIR fluorescence imaging system.

The concentration of $\mathrm{Ag}$ in $\mathrm{Ag}_{2} \mathrm{~S}$ was used to indicate the concentration of probe. A certain amount of $\mathrm{Ag}_{2} \mathrm{~S}$ was taken out at room temperature, after the chloroform completely evaporated, $\mathrm{HNO}_{3}$ was added to dissolve it, titrated with $\mathrm{NH}_{4} \mathrm{SCN}$ (ferric ammonium alum as indicator), when the solution turned red, the titration end point was reached, then the concentration could be calculated.

\section{Synthesis of $\mathrm{Ag}_{2} \mathrm{~S} @ D S P E-P E G_{2000}-\mathrm{FA}\left(\mathrm{Ag}_{2} \mathrm{~S} @ D P-F A\right)$}

According to the literature [35], $2 \mathrm{~mL}$ DMSO, $1 \mathrm{~mL}$ pyridine, $10 \mathrm{mg}$ folic acid, $13 \mathrm{mg}$ dicyclohexyl carbodiimide (DDC) and $4 \mathrm{mg}$ DSPE-PEG ${ }_{2000}-\mathrm{NH}_{2}\left(\mathrm{DP}-\mathrm{NH}_{2}\right)$ were joined in a $10 \mathrm{~mL}$ round bottom flask, stirred for $4 \mathrm{~h}$ in dark environment. The pyridine was removed by suspension, the remaining solution was dialyzed twice in $4.2 \mathrm{~g} / \mathrm{L} \mathrm{NaHCO}$ solution and three times in deionized water to remove free folic acid. Finally, the solution in dialysis bag was lyophilized to obtain DP-FA and stored in $-20^{\circ} \mathrm{C}$.
$\mathrm{Ag}_{2} \mathrm{~S} @ \mathrm{DP}-\mathrm{FA}$ was attached as positive probe. $4 \mathrm{mg}$ lecithin, $6 \mathrm{mg}$ polyoxyethylene stearate, $2 \mathrm{mg}$ DP, $1 \mathrm{mg}$ DP-FA and $700 \mu \mathrm{L} \mathrm{Ag}_{2} \mathrm{~S}$ joined in a $10 \mathrm{~mL}$ round bottom flask, mixed at room temperature and slowly evaporated to dry, after that, added a small amount of PBS to dissolve. The method of synthesis phospholipid coating $\mathrm{Ag}_{2} \mathrm{~S}$ negative probe without FA ( $\left.\mathrm{Ag}_{2} \mathrm{~S} @ \mathrm{DP}\right)$ was consistent with the positive probe except adding DP-FA.

The probe's stability was characterized by measuring the size and Zeta potential of $\mathrm{Ag}_{2} \mathrm{~S} @ \mathrm{DP}-\mathrm{FA}$ under 4, 25 and $37^{\circ} \mathrm{C}$ respectively at $5,10,15,20,25$ and 30 days.

\section{PAI and PTT evaluation of $\mathrm{Ag}_{2} \mathrm{~S} @ D P-F A$}

Different concentration $\mathrm{Ag}_{2} \mathrm{~S} @ D P$-FA probes $(0,0.1,0.2$, $0.4,0.8$, and $1 \mathrm{mg} / \mathrm{mL}$ ) embedded in $1 \%$ agar gel cylinders were performed quantitatively using single ELISA plate. The photoacoustic image (PAI) was measured at $744 \mathrm{~nm}$ and $0.6 \mathrm{~mJ}$ using a homemade PA system.

$200 \mu \mathrm{L}$ aqueous suspensions containing different concentrations of $\mathrm{Ag}_{2} \mathrm{~S} @ \mathrm{DP}-\mathrm{FA}$ probes were poured into different ELISA plates, and then illuminated by $808 \mathrm{~nm}$ laser with tunable output power density for $5 \mathrm{~min}$. The increase of temperature was monitored and recorded by Thermal Camera.

\section{Cytotoxicity of the $\mathrm{Ag}_{2} \mathrm{~S} @ \mathrm{DP}-\mathrm{FA}$}

HeLa and A549 cells were homogenously inoculated in a 96-well plate for 8 groups, 5 repeated experiments for each group. $\mathrm{Ag}_{2} \mathrm{~S} @ \mathrm{DP}-\mathrm{FA}$ at concentrations of $0,3.2,6.4$, $13,25,50$, and $100 \mu \mathrm{g} / \mathrm{mL}$ were added to the cells. After incubating for $24 \mathrm{~h}, 20 \mu \mathrm{L}$ MTT solution $(5 \mathrm{mg} / \mathrm{mL})$ was added to each well and kept for $4 \mathrm{~h}$, the medium was sucked out and $150 \mu \mathrm{L}$ DMSO was added to dissolved the violet crystals. The 96-well plate was shaken for $15 \mathrm{~min}$, finally the absorbance was measured at $490 \mathrm{~nm}$.

Long-term cytotoxicity of $\mathrm{Ag}_{2} \mathrm{~S} @ \mathrm{DP}-\mathrm{FA}$ was determined by clone formation assay [36]. According to the MTT method, the cells were seeded in a 96-well plate and incubated with different concentration $\mathrm{Ag}_{2} \mathrm{~S} @ \mathrm{DP}-\mathrm{FA}$ $(0,3.2,6.5,13,25$, and $50 \mathrm{mg} / \mathrm{mL})$, besides, 4 parallels were set for each concentration. After $24 \mathrm{~h}$ incubation, about 2000 cells were inoculated in 6-well plates at each concentration. After 7 days culture, they were fixed with $2.5 \%$ glutaraldehyde for $30 \mathrm{~min}$, washed the glutaraldehyde with PBS and added 5\% crystal violet staining for $15 \mathrm{~min}$. Finally, the number of cell communities was counted by Photoshop.

\section{In vitro $\mathrm{FI}$ and $\mathrm{PAI}$}

The positive HeLa cells and negative A549 cells were incubated with $50 \mu \mathrm{g} / \mathrm{mL} \mathrm{Ag}_{2} \mathrm{~S} @ \mathrm{DP}-F A$ and $\mathrm{Ag}_{2} \mathrm{~S} @ \mathrm{DP}$, respectively. After $12 \mathrm{~h}$, the culture medium was aspirated and washed several times with PBS to ensure no 
free probe was presented. The cells were fixed with $4 \%$ paraformaldehyde and imaged by the homemade NIR fluorescence imaging system.

HeLa cells were divided into four groups, treated by $\mathrm{Ag}_{2} \mathrm{~S} @ \mathrm{DP}-\mathrm{FA}, \mathrm{Ag}_{2} \mathrm{~S} @ \mathrm{DP}, 1 \mathrm{mg}$ FA for $1 \mathrm{~h}$ before $\mathrm{Ag}_{2} \mathrm{~S} @$ DP-FA, and blank buffer respectively. After $2 \mathrm{~h}$, the cells were washed by PBS for three times to clean up the uncombined probes. Then the cells were harvested by $0.25 \%$ trypsin-EDTA solution, and collected in $1 \%$ agar gel cylinders with single ELISA plates after centrifuging at $1000 \mathrm{rpm}$ for $8 \mathrm{~min}$ and washing for three times with PBS. The PA signals were measured by the homemade PAI system.

\section{In vitro PTT}

Positive and negative cells were seeded in a 24-well plate for $24 \mathrm{~h}$ prior to treatment respectively. $0.5 \mathrm{~mL}$ positive and negative probes dispersed in culture medium at the same $\mathrm{Ag}$ concentration of $25 \mu \mathrm{g} / \mathrm{mL}$ were added into the wells and incubated respectively. After $2 \mathrm{~h}$, the cells were washed by PBS for three times to clean up the uncombined probes. Then the cells were irradiated for $5 \mathrm{~min}$ using $808 \mathrm{~nm}$ laser with a power density of $1.8 \mathrm{~W} / \mathrm{cm}^{2}$. After that, the cells were stained by calcein acetoxymethyl ester (calcein-AM) for 5 min, and observed by inverted optical fluorescence microscope.

\section{TEM of cell uptake probes}

Similar to fluorescence test, after incubation, HeLa and A549 cells were immobilized with $1 \% \mathrm{OsO}_{4}$, then treated with different concentration ethanol (50, 70, 80, 85, 90, 95 and $100 \%)$, resined $48 \mathrm{~h}$ in the Epon 812 at $60{ }^{\circ} \mathrm{C}$. Ultrathin slides were cut and observed by TEM.

\section{In vivo toxicity of the probe}

$50 \mathrm{BALB} / \mathrm{c}$ mice (male, SPF, 4 weeks) were divided into 5 groups randomly, half mice of each group were injected with $\mathrm{Ag}_{2} \mathrm{~S} @ \mathrm{DP}$ probe $(108 \mathrm{mg} \mathrm{Ag} / \mathrm{kg})$ by tail vein and the others were injected with the same volume of PBS. $300 \mu \mathrm{L}$ blood was obtained at $0,6 \mathrm{~h}, 1,3,7$ and 15 days, $200 \mu \mathrm{L}$ for liver enzyme analysis, AST and ALT, other $100 \mu \mathrm{L}$ for blood analysis, RBC, WBC, PLT, and HGB. At the same time, the heart, liver, spleen, lung, kidney and small intestine were collected, fixed by $4 \%$ paraformaldehyde, dehydrated, embedded, sliced and HE staining, placed under the optical microscope for histopathological examination. All animal experiments were approved by the Animal Experimental Ethics Committee of Huazhong University of Science and Technology.

\section{In vivo targeting $\mathrm{Fl}, \mathrm{PAl}$ and $\mathrm{PTT}$}

Several BALB/c nude mice (male, SPF, 4 weeks) were randomly divided into 4 groups, group I and II were inoculated with positive HeLa cells, group III and IV were seeded with negative A549 cells. The dimensions of the tumors were monitored by vernier caliper every 2 days. Once the tumor volume grew to $80 \mathrm{~mm}^{3}, \mathrm{Ag}_{2} \mathrm{~S} @$ DP-FA positive probe $(108 \mathrm{mg} \mathrm{Ag} / \mathrm{kg})$ was injected into group I and III by tail vein, group II and IV were injected with the same amount of $\mathrm{Ag}_{2} \mathrm{~S} @ \mathrm{DP}$ negative probe. The mice were imaged with the NIR fluorescence imaging system at $0 \mathrm{~h}, 5 \mathrm{~min}, 1,2,4,12,24,36$ and $48 \mathrm{~h}$. At the same time point, the heart, liver, spleen, lung, kidney, small intestine and tumor of some mice in group I were collected and imaged by the homemade NIR fluorescence imaging system.

Twenty HeLa tumor-bearing nude mice were randomly divided into 4 groups for PTT. Group I was exposed to NIR laser with an output power density of $2.8 \mathrm{~W} / \mathrm{cm}^{2}$ for $10 \mathrm{~min}$ after tail intravenously injection of $\mathrm{Ag}_{2} \mathrm{~S} @$ DP-FA (108 mg Ag/kg); group II was irradiated for 10 min with injection of $600 \mu \mathrm{L}$ saline solution; group III was tail intravenously injected with $\mathrm{Ag}_{2} \mathrm{~S} @ D P-F A$ (108 $\mathrm{mg} \mathrm{Ag} / \mathrm{kg}$ ) without NIR laser irradiation; group IV was as a blank control without any treatment. Same as group I, positive probe was injected to another batch of tumor-bearing nude mice, in vivo photoacoustic imaging experiment was carried out at different time points. In the experiment, the nude mice were fixed on the stage of the photoacoustic system after anesthesia with $10 \mu \mathrm{L} / \mathrm{g}$ of urethane. The wavelength of laser was 744 or $532 \mathrm{~nm}$ and the laser energy per pulse was $200 \mathrm{~nJ}$.

\section{Results and discussion}

The NIR-II region emission of $\mathrm{Ag}_{2} \mathrm{~S}$ quantum dot can greatly reduce the interference of spontaneous fluorescence from the organism, improve the signal to noise ratio. In addition, the absorption and scattering of light in the NIR-II region are less, so $\mathrm{Ag}_{2} \mathrm{~S}$ has a stronger penetrating ability comparing with the traditional quantum dot, which can be used for the in vivo non-invasive imaging.

As the first step of this study, the hydrophobic $\mathrm{Ag}_{2} \mathrm{~S}$ nanoparticle was synthesized (Fig. 1a), its fluorescence intensity increased significantly accompanying with increasing concentration (Fig. 1b). The spectral characterization showed a wide absorption and $\sim 1100 \mathrm{~nm}$ emission (Fig. 1d). TEM showed that $\mathrm{Ag}_{2} \mathrm{~S}$ had a relatively uniform size about $5 \mathrm{~nm}$ (Fig. 1c). EDS test showed that the sample consisted of $\mathrm{Ag}$ and $\mathrm{S}$ elements, but the molar ratio was less than 2:1 (Fig. 1e), this might be due to the fact that dodecanethiol (DT) contained $\mathrm{S}$, increased the relative content of sulfur. The surface ligand on $\mathrm{Ag}_{2} \mathrm{~S}$ was detected by infrared spectroscopy, results showed that $\mathrm{Ag}_{2} \mathrm{~S}$ had a consistent characteristic of infrared spectroscopy with DT (Fig. 1f), indicating 

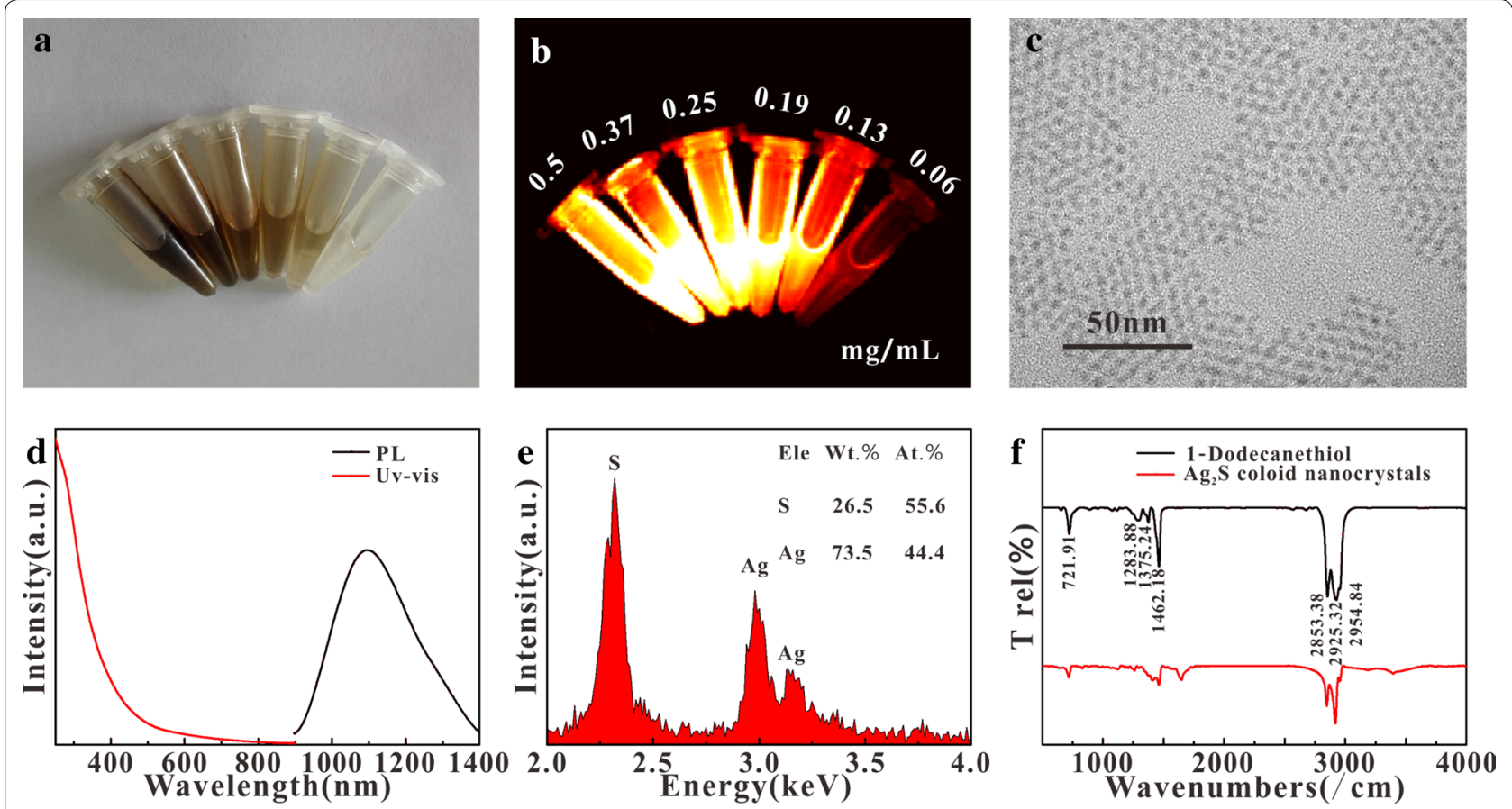

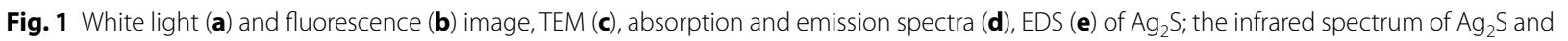
$\mathrm{DT}(\mathbf{f})$

that DT had been successfully attached to the $\mathrm{Ag}_{2} \mathrm{~S}$ surface.

The target molecule FA was attached to DP- $\mathrm{NH}_{2}$ by DDC. To confirm whether or not FA had been successfully connected with DP- $\mathrm{NH}_{2}$, the absorption spectra of FA, DP- $\mathrm{NH}_{2}$, and DP-FA were measured (Fig. 2a). The results showed that the peak of FA was at $280 \mathrm{~nm}$, while DP-FA had an obvious absorption at $280 \mathrm{~nm}$ comparing with the DP- $\mathrm{NH}_{2}$. In addition, the Zeta potential of these materials were also measured (Fig. 2a, insert). DP- $\mathrm{NH}_{2}$ was $+29.4 \mathrm{mV}$ because it had amino group; for DP-FA, the FA possessed two carboxyl groups, even if one of them was linked with DP- $\mathrm{NH}_{2}$, the other carboxyl group also led to negative charge at $-26.4 \mathrm{mV}$. After modifying $\mathrm{Ag}_{2} \mathrm{~S}$ particles, it was found that a higher negative potential $(-30.84 \mathrm{mV})$ was obtained than DP-modified particles without FA $(-21.8 \mathrm{mV})$. All these results confirmed that FA had been successfully conjugated with DP- $\mathrm{NH}_{2}$.

The size of $\mathrm{Ag}_{2} \mathrm{~S} @ \mathrm{DP}-\mathrm{FA}$ was about $200 \mathrm{~nm}$ measured by dynamic light scattering method (Fig. 2b). TEM showed a size of about $50 \mathrm{~nm}$ (Fig. 2c). This phenomenon might be due to the fact that the former was the hydrated size [37]. The stability of $\mathrm{Ag}_{2} \mathrm{~S} @ D P-F A$ was also measured (Fig. 2d, e). The results showed that the size and potential of $\mathrm{Ag}_{2} \mathrm{~S} @ \mathrm{DP}-\mathrm{FA}$ had no obvious change at different temperatures within 30 days, indicating a good stability.
$\mathrm{Ag}_{2} \mathrm{~S} @ \mathrm{DP}-\mathrm{FA}$ had strong absorption during the visible and NIR region. There were good PA response and PTT effect under certain wavelength laser irradiation. The in vitro photoacoustic and photothermal experiments of probe were carried out. Results showed it had obvious PA response under $744 \mathrm{~nm}$ laser irradiation. It could be seen that accompanying with the increasing Ag concentration, PA signal generated by $\mathrm{Ag}_{2} \mathrm{~S} @ \mathrm{DP}-\mathrm{FA}$ was strengthened (Fig. 2f) with a great linear relationship $\left(R^{2}=0.9931\right)$, indicating good ability of PAI.

It was found that $\mathrm{Ag}_{2} \mathrm{~S} @ \mathrm{DP}-\mathrm{FA}(2.5 \mathrm{mg} / \mathrm{mL})$ dispersed in deionized water, PBS and fetal bovine serum (FBS) all showed perfect photothermal conversion under NIR laser irradiation (Fig. 3a, d). And when the power density of NIR laser was increased, the temperature of aqueous dispersion of $\mathrm{Ag}_{2} \mathrm{~S} @ \mathrm{DP}-\mathrm{FA}(1.0 \mathrm{mg} / \mathrm{mL})$ also increased (Fig. 3b, e). Furthermore, when $\mathrm{Ag}_{2} \mathrm{~S} @ D P-F A$ concentration increased, temperature of the aqueous dispersion could be elevated up to higher temperature (Fig. 3c, f). However, the temperature increment with the increase of concentration was not obvious when the concentration was above $2.5 \mathrm{mg} / \mathrm{mL}$. Comparatively, the control experiment of deionized water showed the temperature increment less than $1{ }^{\circ} \mathrm{C}$ under the same experimental conditions. These results indicated that $\mathrm{Ag}_{2} \mathrm{~S}$ probe had excellent photothermal conversion capability. 


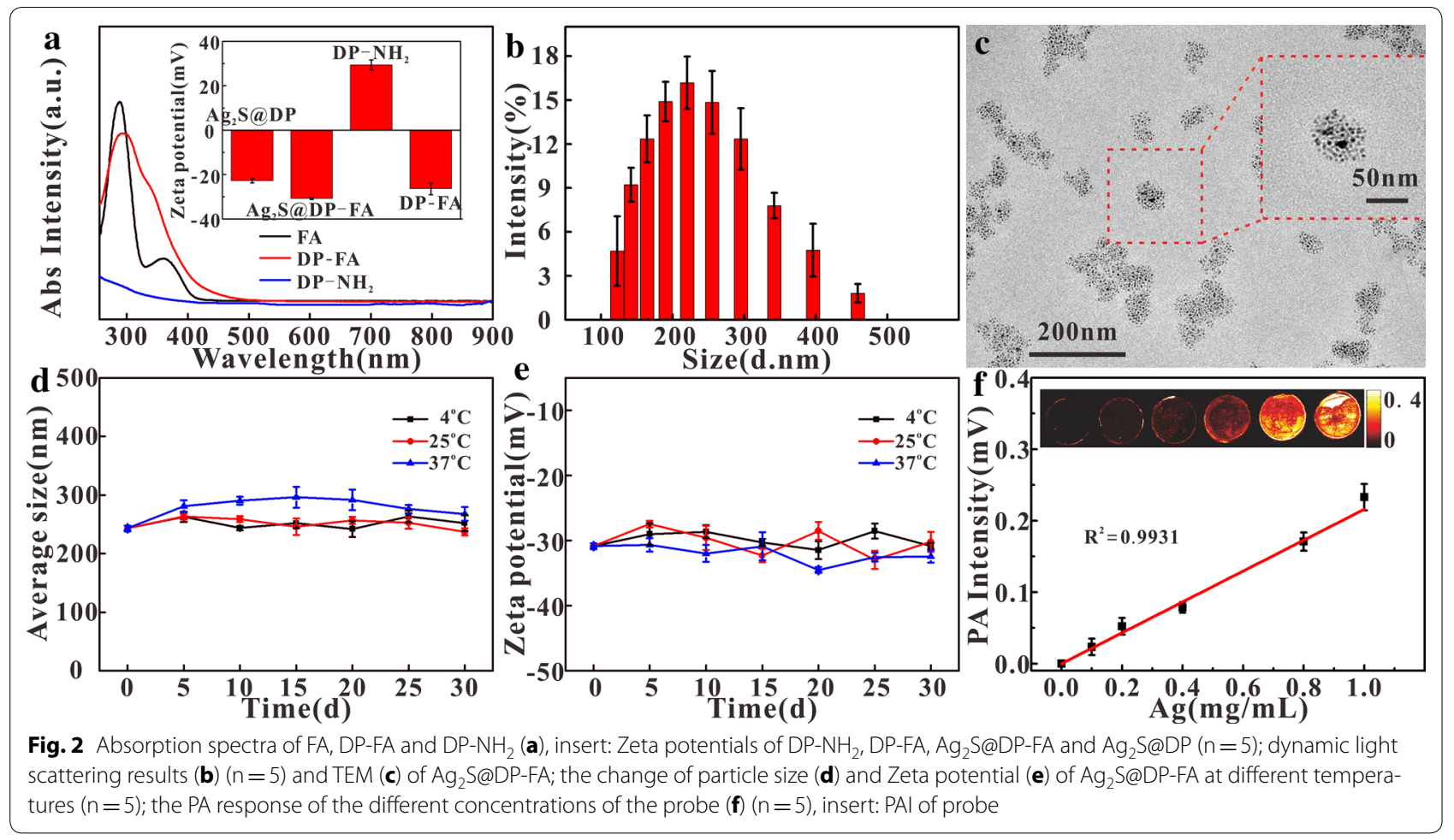

The toxicity of the probe was the key for application. The cytotoxicity of $\mathrm{Ag}_{2} \mathrm{~S} @ \mathrm{DP}-\mathrm{FA}$ probe was investigated by MTT assay. HeLa and A549 cells were incubated for $24 \mathrm{~h}$ with different concentration probe (Ag: 0, 1.6, 3.2, $6.5,13,25,50$, and $100 \mu \mathrm{g} / \mathrm{mL}$ ). Succinate dehydrogenase in the mitochondria of living cells could reduce MTT to blue-violet crystals that could deposit in cells, whereas dead cells had no this function [38]. Results showed that when the concentration of $\mathrm{Ag}$ was up to $50 \mu \mathrm{g} / \mathrm{mL}$, the cells still had near $80 \%$ survival (Fig. 4). Long-term cytotoxicity experiment was investigated by the colony formation assay. Cell viability was estimated through the number of cell population (Fig. 4b). It was found the results (Fig. 4c) were consistent with the MTT results, indicating that $\mathrm{Ag}_{2} \mathrm{~S} @$ DP-FA probe had a lower cytotoxicity.

Then the active target ability of the probe was examined. HeLa and A549 cells were incubated with $50 \mu \mathrm{g} /$ $\mathrm{mL} \mathrm{Ag} 2 \mathrm{~S} @ \mathrm{DP}-\mathrm{FA}$ and $\mathrm{Ag}_{2} \mathrm{~S} @ \mathrm{DP}$. The results showed that HeLa cells incubated with $\mathrm{Ag}_{2} \mathrm{~S} @ D P-F A$ were turned yellow and had the strongest fluorescence (Fig. 5a); while A549 cells incubated with $\mathrm{Ag}_{2} \mathrm{~S} @ \mathrm{DP}-\mathrm{FA}$ and HeLa cells incubated with $\mathrm{Ag}_{2} \mathrm{~S} @ \mathrm{DP}$ were only observed faint yellow, and the fluorescence of the two was weak; the other groups looked white and no fluorescence was observed. The above results showed that $\mathrm{Ag}_{2} \mathrm{~S} @ \mathrm{DP}-\mathrm{FA}$ could specifically bind to FA receptors which high expressed on HeLa cells, and had no effective targeting ability for A549 cells which low expressed FA receptor. Likewise, negative probe $\mathrm{Ag}_{2} \mathrm{~S} @ \mathrm{DP}$ had no effective targeting binding to HeLa and A549 cells. This experiment showed that the $\mathrm{Ag}_{2} \mathrm{~S} @ \mathrm{DP}-\mathrm{FA}$ probe could be used as an active targeting imaging diagnostic reagent for some tumors that high expressed FA receptors such as HeLa, and had the ability for target FI.

PAI was also conducted at the cellular level. HeLa cells were incubated with different probes for PAI. The results showed that both $\mathrm{Ag}_{2} \mathrm{~S} @ \mathrm{DP}-\mathrm{FA}$ and $\mathrm{Ag}_{2} \mathrm{~S} @ \mathrm{DP}$ incubating HeLa cells had PA signals (Fig. 5b), indicating negative probe also combined to HeLa cells through nonspecific adsorption, this was consistent with the FI results (Fig. 5a). But there was great significant difference between them $(\mathrm{p}<0.01)$, meant $\mathrm{Ag}_{2} \mathrm{~S} @ \mathrm{DP}-\mathrm{FA}$ combined to HeLa cells more easily than $\mathrm{Ag}_{2} \mathrm{~S} @ \mathrm{DP}$. To verify this further, FA was added into the cell culture flask before $1 \mathrm{~h}$ of adding $\mathrm{Ag}_{2} \mathrm{~S} @ \mathrm{DP}-\mathrm{FA}$, significant difference was obtained $(\mathrm{p}<0.05)$. It was because that the FA receptors on the cell surface were combined with free FA firstly, resulting in subsequent $\mathrm{Ag}_{2} \mathrm{~S} @ \mathrm{DP}$-FA could not combine to HeLa. These experiments above confirmed that $\mathrm{Ag}_{2} \mathrm{~S} @$ DP-FA had good active target ability.

FA as a target molecule on the probe, its targeting could be also verified by the effect of PTT. When $\mathrm{Ag}_{2} \mathrm{~S} @$ DP-FA positive probe was incubated with HeLa cells and irradiated with laser for $5 \mathrm{~min}$, calcein staining revealed that the cells in the non-irradiated region had significant 

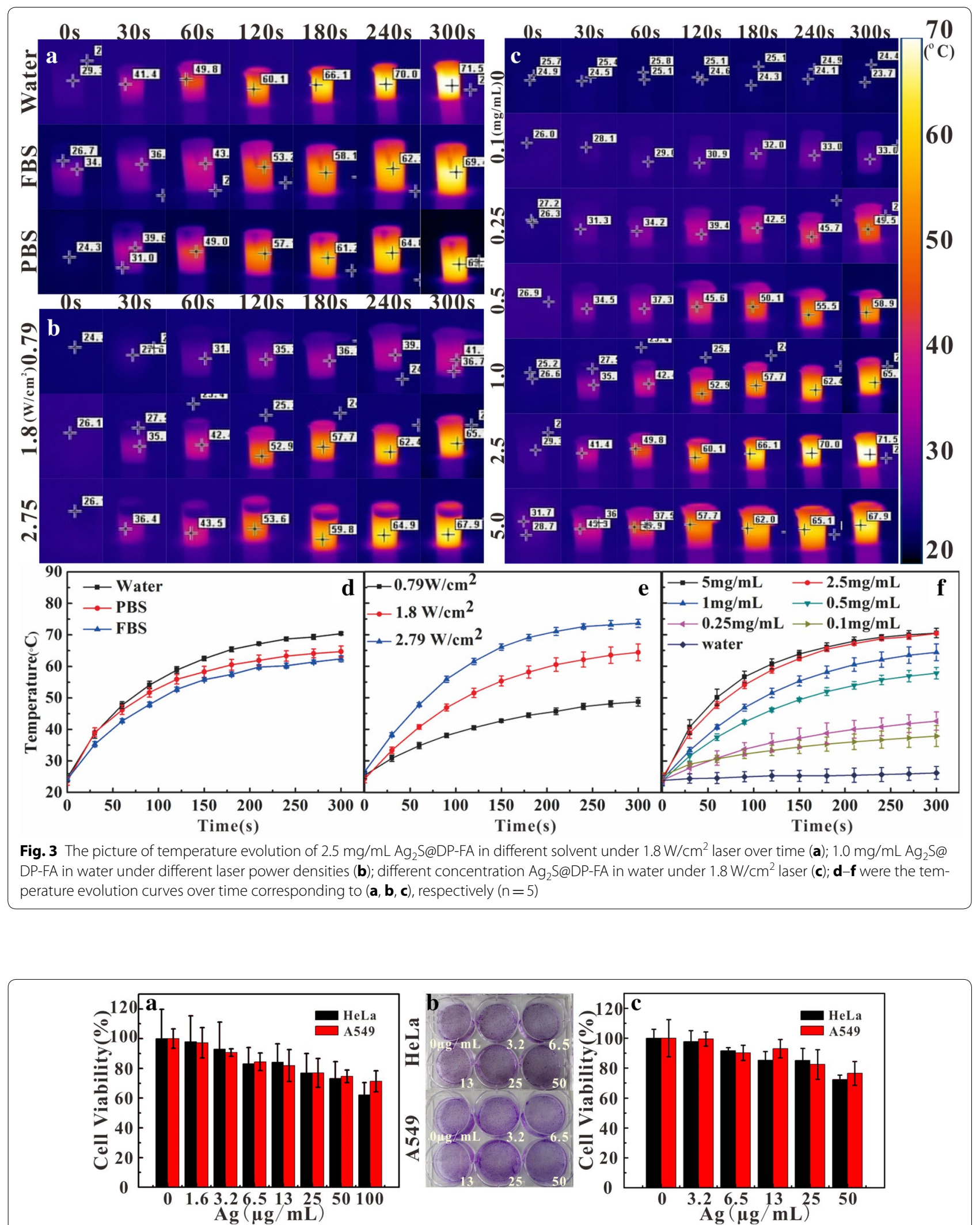

Fig. 4 MTT test of $\mathrm{Ag}_{2} \mathrm{~S} @ D P-F A(\mathbf{a})(n=5)$; white light results $(\mathbf{b})$ and cell community data statistics $(\mathbf{c})(n=5)$ of colony formation assay method to detect the long-term toxicity of the probe 


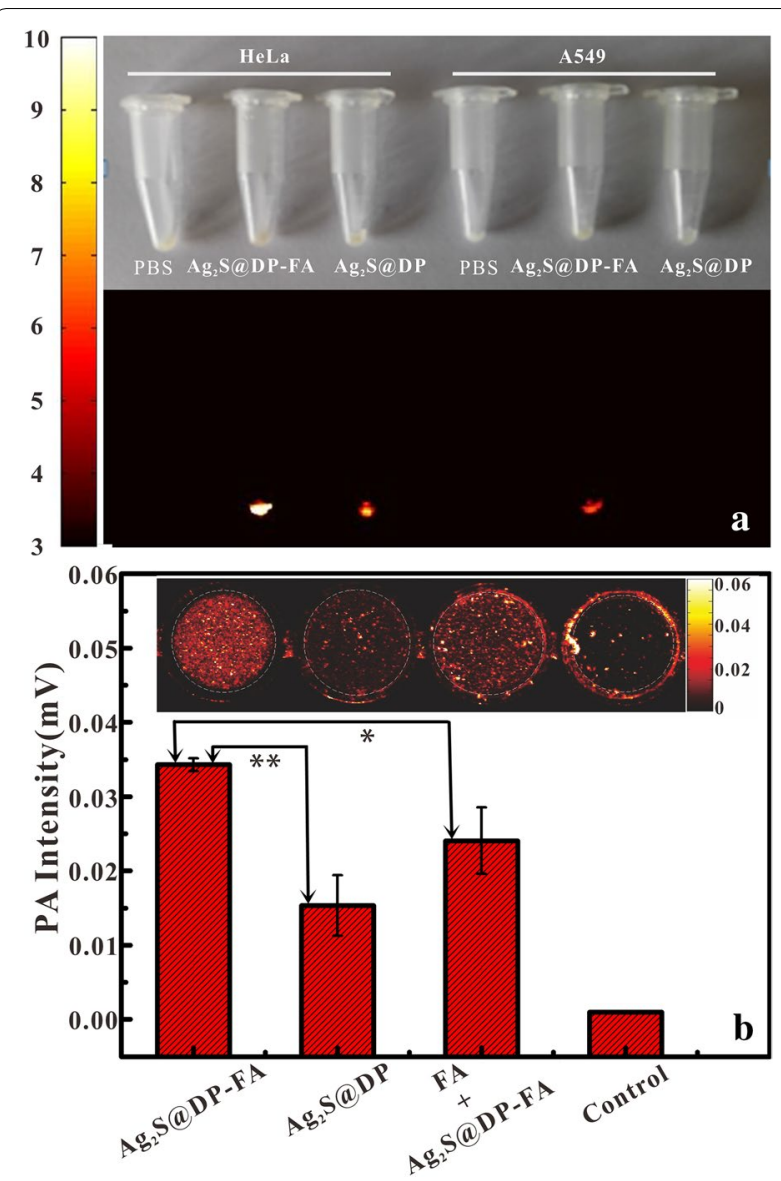

Fig. 5 White light and $\mathrm{FI}$ results of different cells incubated with different probes (a) and photoacoustic response results of different probe-labeled positive HeLa cells $(\mathbf{b})(n=5),{ }^{*}$ meant significant difference $(p<0.05),{ }^{* *}$ meant great significant difference $(p<0.01)$

fluorescence, while the irradiated area showed only extremely weak fluorescence (Fig. 6). Calcein is a cell dyeing reagent which could stain live cell producing green emission except dead one [39]. If HeLa cells were only incubated with $\mathrm{Ag}_{2} \mathrm{~S} @ \mathrm{DP}-\mathrm{FA}$ without any irradiation, the cells showed obvious green fluorescence. To rule out the possibility of death by laser, HeLa cells were exposed to laser irradiation directly under same factors, the results showed that the cells still had bright green fluorescence, indicating that cell death was caused by the thermal effect of $\mathrm{Ag}_{2} \mathrm{~S} @ \mathrm{DP}-\mathrm{FA}$. In order to investigate the ability of active targeting of probe, HeLa cells were incubated with $\mathrm{Ag}_{2} \mathrm{~S} @ \mathrm{DP}$, the results showed after laser irradiation the cells still had green fluorescent, meant negative probe could not target HeLa effectively. It seemed opposite to the results of PAI (Fig. 5b), but it was understandable, although there was nonspecific adsorption of $\mathrm{Ag}_{2} \mathrm{~S} @ \mathrm{DP}$, not in sufficient quantities to enhance temperature to kill cells, so they were still alive. For control experiments, no matter what kind of conditions above, as low FA receptor expression cell, A549 all present obvious green fluorescence. These experiments proved that only HeLa cells incubated with $\mathrm{Ag}_{2} \mathrm{~S} @ \mathrm{DP}-\mathrm{FA}$ could be killed by laser irradiation, which could fully demonstrate $\mathrm{Ag}_{2} \mathrm{~S} @ \mathrm{DP}-\mathrm{FA}$ had good ability of active targeting and PTT.

TEM was used to further investigate the uptake of different probes by HeLa cells and A549 cells (Fig. 7). The results showed that comparing with the PBS control group (Fig. 7a, d), black particles appeared in the cytoplasm of HeLa (Fig. 7b) and A549 (Fig. 7e) cells in $\mathrm{Ag}_{2} \mathrm{~S} @$ DP-FA group, which confirmed that both HeLa and A549 cells could ingest a certain amount of $\mathrm{Ag}_{2} \mathrm{~S} @ D P-F A$ probes by endocytosis, the amount of probes in HeLa cells was significantly higher than A549 cells. This result was consistent with the results of the FI and PAI because HeLa cells expressed more FA receptors than A549 cells, and thus could bind more targeting probes. There were also a few probes in the HeLa and A549 cytoplasm in $\mathrm{Ag}_{2} \mathrm{~S} @ \mathrm{DP}$ group, and probes in the HeLa cells (Fig. 7c) were slightly more than A549 cells (Fig. 7f). This was also consistent with the results of FI. Overall, the amount of $\mathrm{Ag}_{2} \mathrm{~S} @ \mathrm{DP}-\mathrm{FA}$ probes in the HeLa cytoplasm was significantly the highest than the other control groups, this was consistent with the FI and PAT and PTT experiments, indicating that the $\mathrm{Ag}_{2} \mathrm{~S} @ \mathrm{DP}-\mathrm{FA}$ probe had a good active targeting ability and could be used as a target imaging diagnostic reagent.

In order to evaluate the in vivo safety of the probe, the blood biochemical indexes in mice were examined after injection of the probe. The results showed that there was no significant difference in white blood cell (WBC) (Fig. 8a), red blood cell (RBC) (Fig. 8b), and hemoglobin (HGB) (Fig. 8c) between the probe group and the PBS control group. The platelet (PLT) in probe group (Fig. 8d) was significantly reduced after 1 day but returned to normal at 7 days, indicating the probe did not cause irreversible damage to the mice. In addition, the effect of probe on liver function was investigated by testing the level of alanine aminotransferase (ALT) (Fig. 8e) and aspartate aminotransferase (AST) (Fig. 8f). The results showed that ALT and AST contents significantly changed after injection then backed to normal levels at 3 days, PBS group also had similar change. The reason for this short rise was due to the use of anesthetics, which might increase liver enzyme activity and cause AST and ALT in the mice blood to be temporarily rising for several hours [40]. The above results showed that our synthetic probe had good biosafety.

In addition to blood analysis, the effects of probes on mice organs were also examined. Comparing the $\mathrm{HE}$ staining results of PBS group with probe group at $6 \mathrm{~h}, 1$, 3,7 and 15 days after injection (Fig. 9), it was found that 


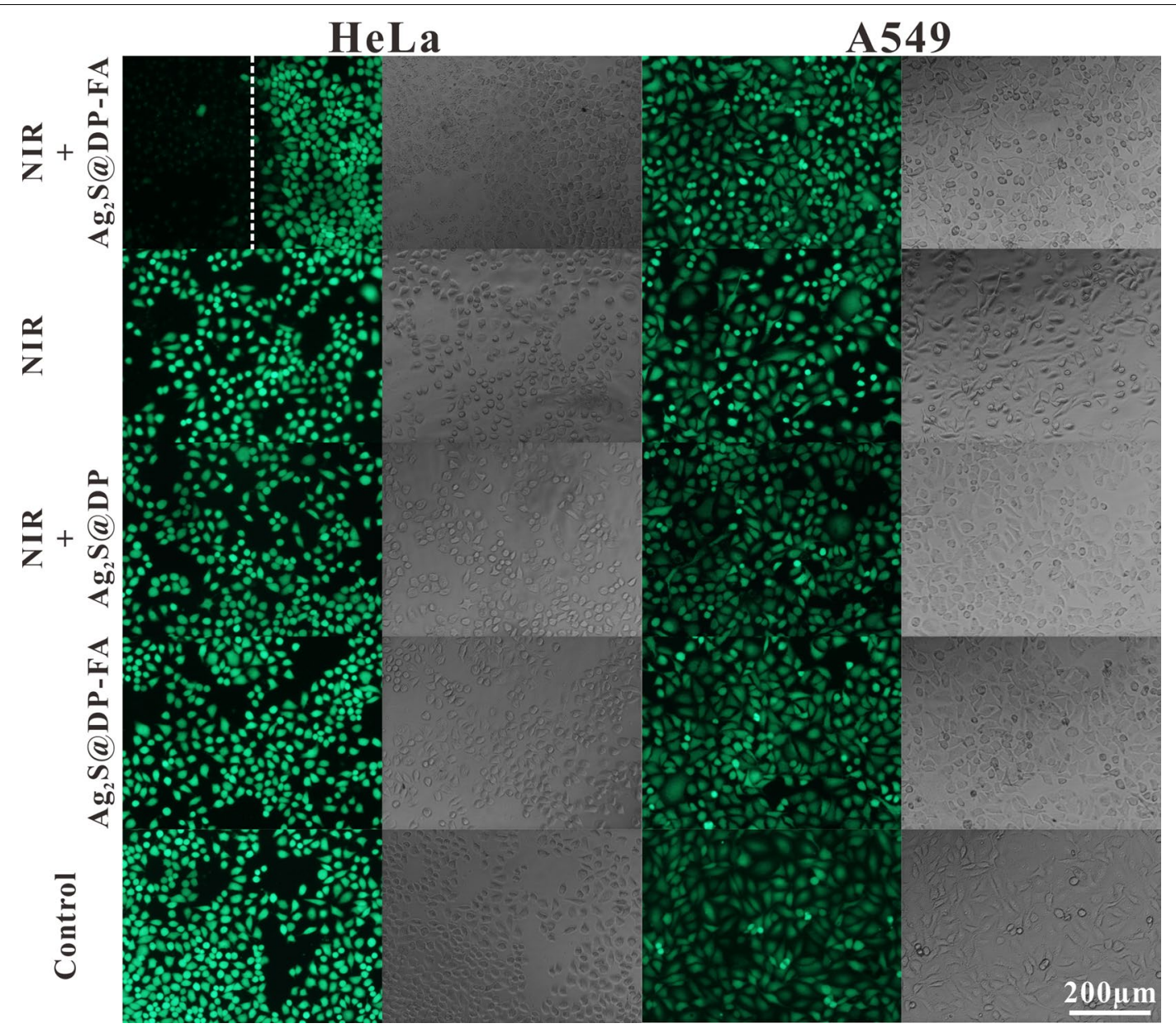

Fig. 6 HeLa and A549 were incubated with positive probe ( $\left.\mathrm{Ag}_{2} \mathrm{~S} @ \mathrm{DP}-\mathrm{FA}\right)$ or negative probe $\left(\mathrm{Ag}_{2} \mathrm{~S} @ \mathrm{DP}\right)$, and then treated with or without NIR laser irradiation. Cells were stained by calcein-AM. Laser power was $1.8 \mathrm{~W} / \mathrm{cm}^{2}$, and irradiation time was $5 \mathrm{~min}$. White dotted line was the border of laser irradiation

the tissue structure of heart, liver, spleen, lung, kidney, and small intestine did not change significantly, indicating that the probe had little effect on these organs, further proved that our probe had good biosecurity.

After that, the in vivo active targeting imaging ability of the probe was examined. The $\mathrm{Ag}_{2} \mathrm{~S} @ \mathrm{DP}-\mathrm{FA}$ and $\mathrm{Ag}_{2} \mathrm{~S} @$ DP probes were injected into HeLa tumor-bearing nude mice and A549 tumor-bearing nude mice by tail vein, and they were imaged by homemade NIR fluorescence imaging system at different times. The results showed that $\mathrm{Ag}_{2} \mathrm{~S} @ \mathrm{DP}-\mathrm{FA}$ spread all over HeLa tumor-bearing nude mouse after $5 \mathrm{~min}$, the tumor site had obvious fluorescence after $1 \mathrm{~h}$ and showed brightest fluorescence at $12 \mathrm{~h}$, then it began to decay, after $36 \mathrm{~h}$, the tumor site still had a certain intensity of fluorescence (Fig. 10a). While the HeLa tumor-bearing nude mouse injected with $\mathrm{Ag}_{2} \mathrm{~S} @$ DP had a weaker fluorescence in tumor at $4 \mathrm{~h}$, and the fluorescence disappeared at $24 \mathrm{~h}$ (Fig. 10b). As for A549 tumor-bearing nude mice, no significant fluorescence enhancement were observed at the tumor sites (Fig. 10c, d), indicating that the probe did not enrich at the tumor sites. This series of in vivo fluorescence imaging were consistent with in vitro FI results, further showed that $\mathrm{Ag}_{2} \mathrm{~S} @ \mathrm{DP}-\mathrm{FA}$ probe had a good active targeting imaging capability.

Next, the distribution of the probe in the nude mice was examined. At different times, the main organs and tumor were collected for FI. The results showed that the probe had more residues in the liver, spleen and lungs, and had fewer residues in the heart, kidneys and small intestine (Fig. 11). With the extension of time, the probe gradually discharged from the organs. Tumor site began to light at $1 \mathrm{~h}$, the fluorescence effect was more obvious at $4 \mathrm{~h}$, and reached the maximum at $12 \mathrm{~h}$, then began to weaken and continued to $36 \mathrm{~h}$, same with in vivo targeted FI.

Once the tumor volumes were about $80 \mathrm{~mm}^{3}$, in vivo PAI of nude mice tail intravenously injected with $\mathrm{Ag}_{2} \mathrm{~S} @$ 

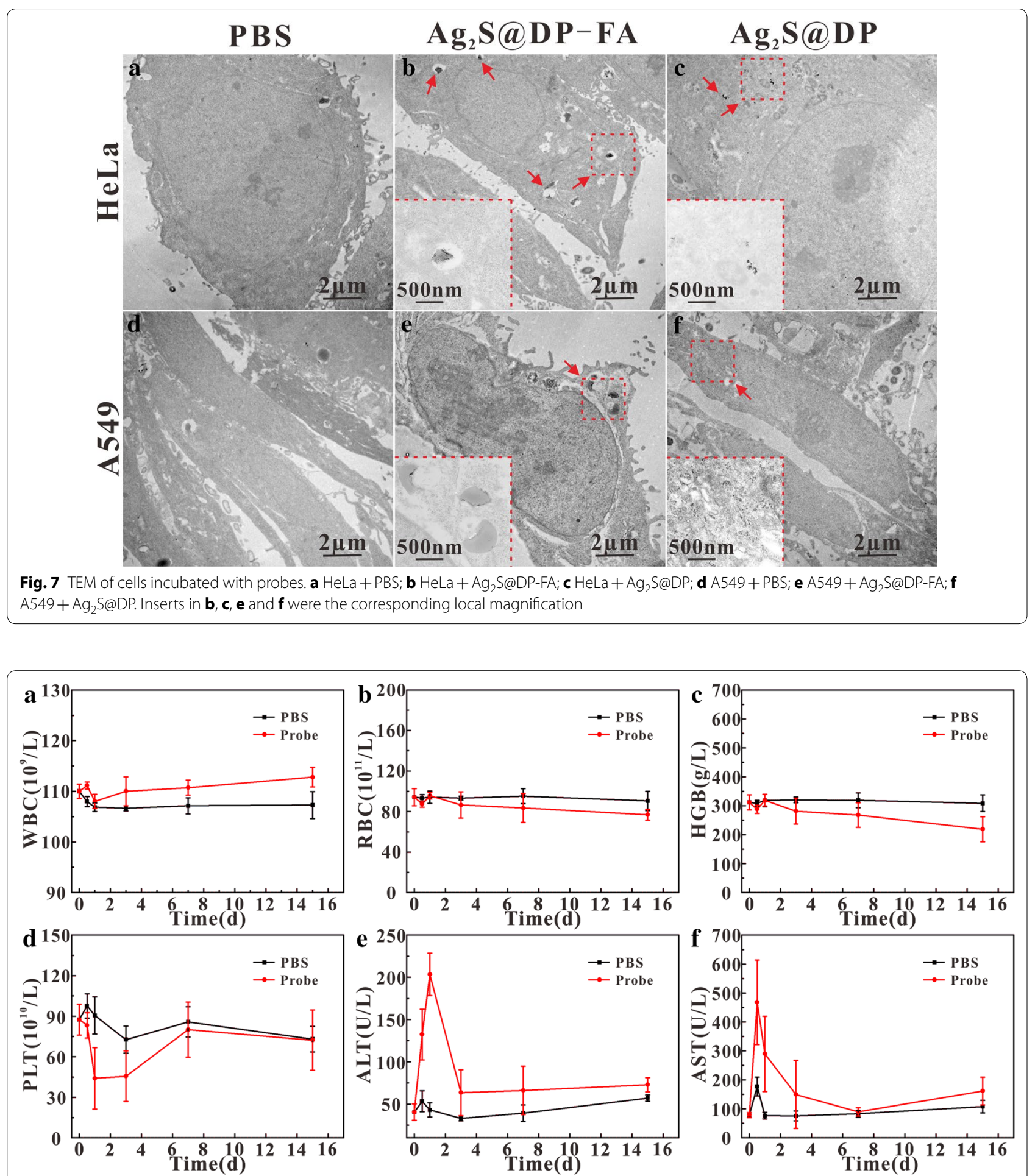

Fig. 8 Blood sample analysis after injection $(n=5)$. a WBC; b RBC; $\mathbf{c H G B}$; d PLT; e ALT; f AST

DP-FA was carried out using $744 \mathrm{~nm}$ laser. The PAI system has high lateral resolution $(\sim 4 \mu \mathrm{m})$, it showed before tail intravenous injection, there was no PA signal on the tumor (Fig. 12c). After injection, PA signal intensity of tumor showed significant enhancement comparing with the background (Fig. 12b). It indicated that the accumulation of $\mathrm{Ag}_{2} \mathrm{~S} @ \mathrm{DP}-\mathrm{FA}$ into the tumor was increased in the initial several hours, and reached the highest after 


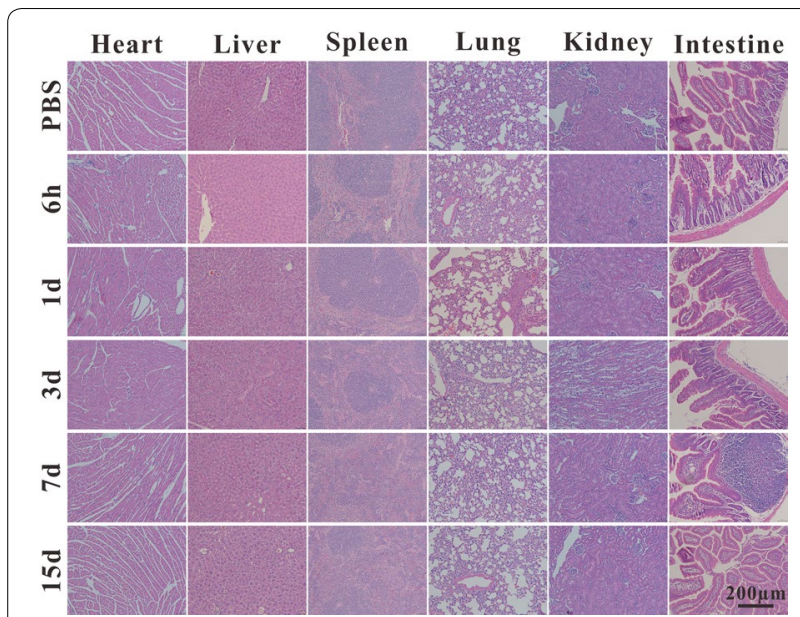

Fig. 9 The HE staining results of the main organ after injecting PBS and probe for $6 h, 1,3,7,15$ days shown in from top to bottom, from the left to right was heart, liver, spleen, lung, kidney, and intestine

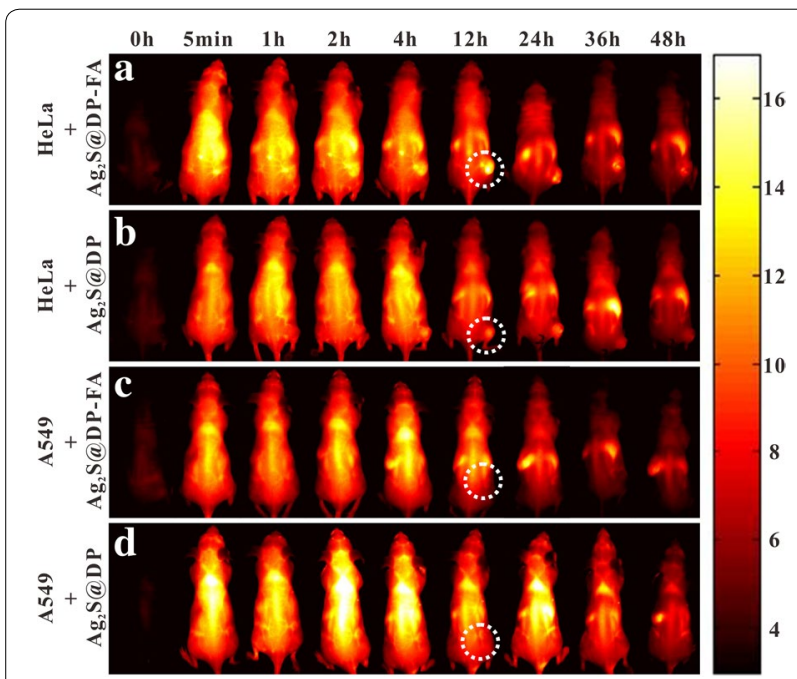

Fig. $10 \mathrm{Fl}$ of the target tumor in the nude mice at $0 \mathrm{~h}, 5 \mathrm{~min}, 1,2,4$, $8,12,24,36$ and $48 \mathrm{~h}$ (the tumor site in the dashed line cycle). a HeLa tumor-bearing nude mice $+\mathrm{Ag}_{2} \mathrm{~S} @ D P-F A ; \boldsymbol{b}$ HeLa tumor-bearing nude mice $+\mathrm{Ag}_{2} \mathrm{~S} @ D P ; \mathbf{c}$ A549 tumor-bearing nude mice + $\mathrm{Ag}_{2} \mathrm{~S} @$ $\mathrm{DP}-\mathrm{FA} ; \mathbf{d}$ A549 tumor-bearing nude mice + $\mathrm{Ag}_{2} \mathrm{~S} @ \mathrm{DP}$

$12 \mathrm{~h}$, the PA response became weak after $24 \mathrm{~h}$ (Fig. $12 \mathrm{~d}-$ j). This result was consistent with the FI. To determine whether or not the imaging was indeed at a vascular site of the tumor, PA signal of the same tumor region was also detected under $523 \mathrm{~nm}$, it showed that there were rich blood vessels due to strong PA response of hemoglobin at this wavelength (Fig. 12k), the pattern was consistent with the PAI at $12 \mathrm{~h}$ (Fig. 12i). It demonstrated PA signal at $744 \mathrm{~nm}$ was derived from $\mathrm{Ag}_{2} \mathrm{~S} @ \mathrm{DP}-\mathrm{FA}$ targeted to the tumor.

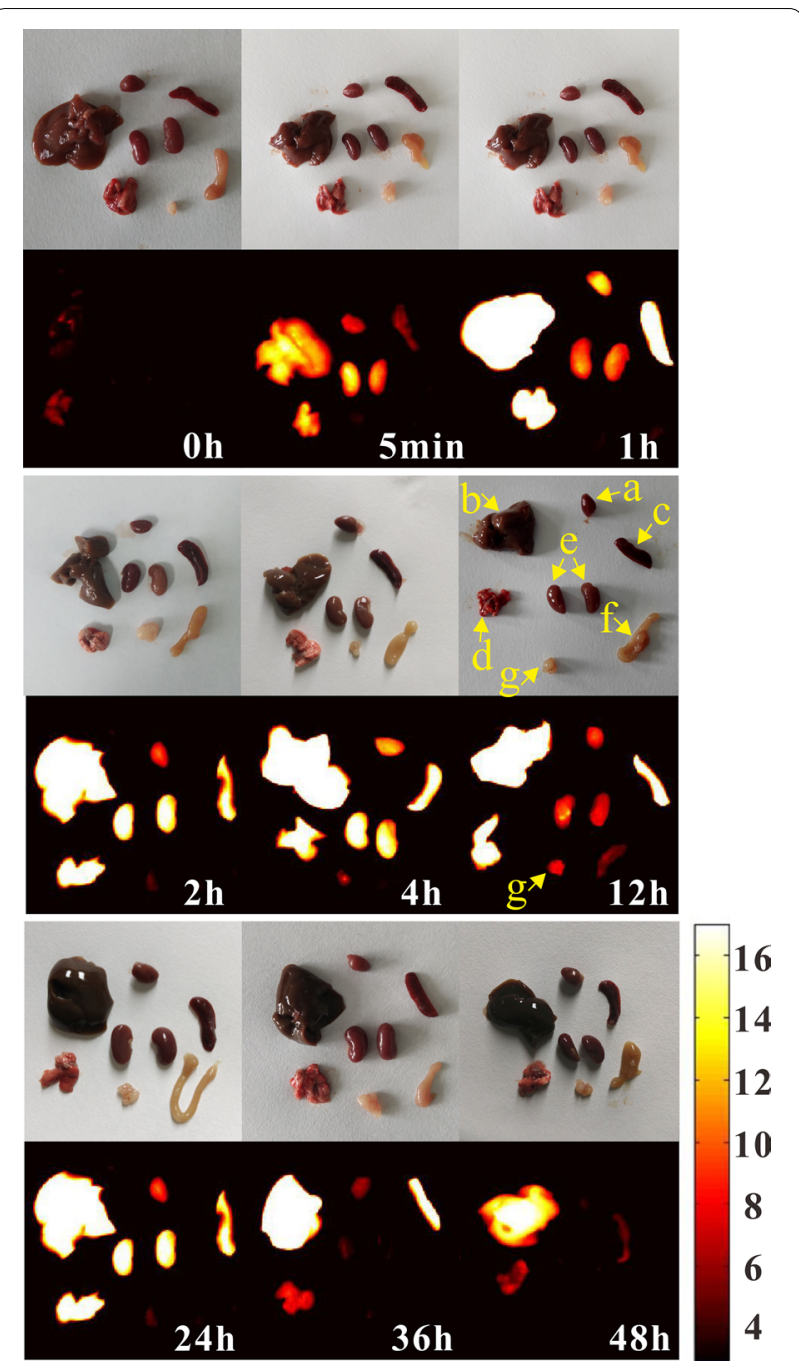

Fig. 11 White and fluorescence imaging of heart (a), liver (b), spleen (c), lung (d), kidney (e), small intestine ( $\mathrm{f}$ ), and tumor ( $\mathrm{g}$ ) in HeLa tumor-bearing nude mice at $0 \mathrm{~h}, 5 \mathrm{~min}, 1,2,4,8,12,24,36$ and $48 \mathrm{~h}$ after injection of $\mathrm{Ag}_{2} \mathrm{~S} @ D P-F A$

Based on efficient in vitro PTT effect and in vivo FI and PAI, in vivo PTT was carried out further. After undergoing laser irradiation for $10 \mathrm{~min}$, the temperature of bearing tumor on nude mouse tail intravenously injected with $\mathrm{Ag}_{2} \mathrm{~S} @ \mathrm{DP}-\mathrm{FA}$ could rise up to $67{ }^{\circ} \mathrm{C}$ (Fig. 13a, c), which would kill the tumor adequately. As control group, the temperature of bearing tumor on nude mouse tail intravenously injected with saline just rose up $10{ }^{\circ} \mathrm{C}$ (Fig. 13b, c), there was great significant difference between them $(\mathrm{p}<0.01)$, indicating that the $\mathrm{Ag}_{2} \mathrm{~S} @$ DP-FA probe targeted to the tumor exerted significant PTT effect. The region of tumor treated with $\mathrm{Ag}_{2} \mathrm{~S} @$ DP-FA was charred immediately upon laser irradiation and further became black scar after 1 day, as time went on, the scar of tumor was healed little by little, and 


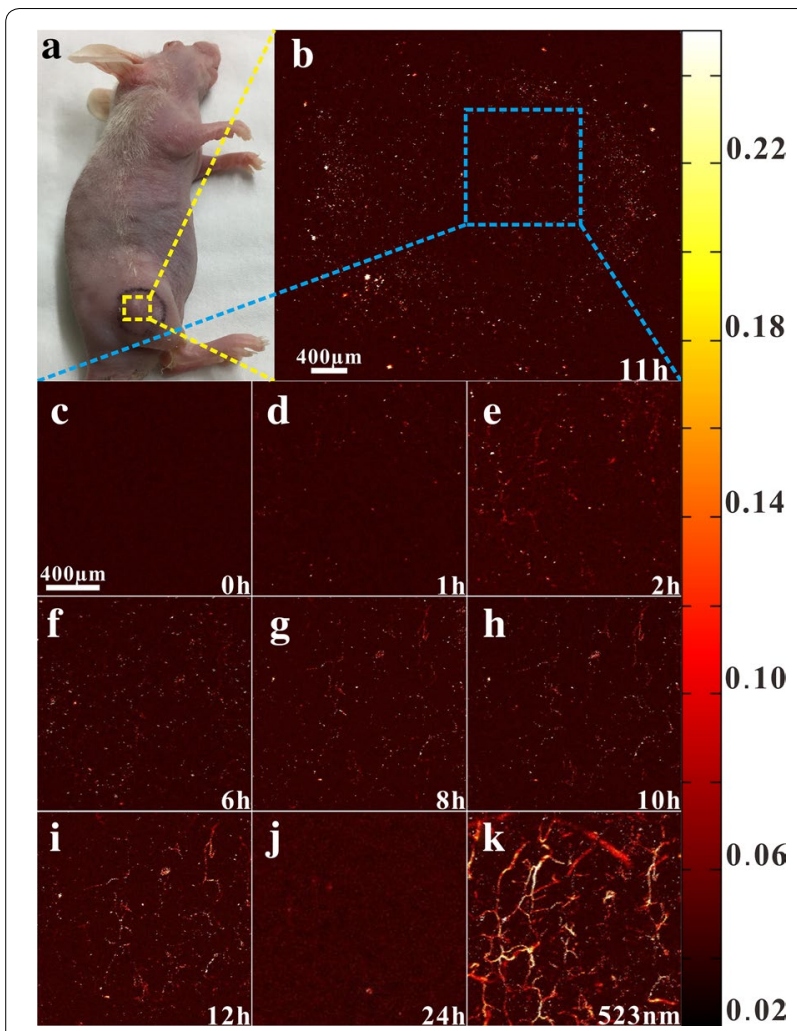

Fig. 12 In vivo PAl of the nude mouse tail intravenously injected with $\mathrm{Ag}_{2} \mathrm{~S} @ D P-F A(\mathbf{a})$; the whole tumor after injecting $11 \mathrm{~h}$ under $744 \mathrm{~nm}$ laser excitation (b); the same part of tumor at different times under $744 \mathrm{~nm}$ laser excitation $(\mathbf{c}-\mathbf{j})$; the same part of tumor under $523 \mathrm{~nm}$ laser excitation $(\mathbf{k})$ became remarkable recovery finally (Fig. 13d), suggesting the cancer was killed by high temperature. Actually, the group injected with $\mathrm{Ag}_{2} \mathrm{~S} @ \mathrm{DP}-\mathrm{FA}$ and underwent laser irradiation was completely cured without reoccurrence after 60 days investigation. H\&E stain of tumor tissue was further conducted to reveal the therapeutic mechanism. It was found that apparent extensive necrosis appeared in the group treated with $\mathrm{Ag}_{2} \mathrm{~S} @ \mathrm{DP}-\mathrm{FA}$ and laser irradiation, however, no obvious malignant necrosis was found in the other three groups (Fig. 13e-h). All the results demonstrated that $\mathrm{Ag}_{2} \mathrm{~S} @ \mathrm{DP}-\mathrm{FA}$ had good ability of target and PTT.

The in vivo treatment toxicity was always a great concern for nanomaterials used in biomedicine, a series of works on it had been done. The changes in body weight of nude mice in four different treatment groups were recorded, and the results showed that PTT did not significantly alter body weight (Fig. 14a), indicating that treatment was safe, no significant side effect on the growth of nude mice. The tumor volumes were also measured (Fig. 14b). All irradiated tumors on mice injected with $\mathrm{Ag}_{2} \mathrm{~S} @ \mathrm{DP}-\mathrm{FA}$ disappeared and were cured without recurrence, there was great significant difference between the experiment group and the control groups $(\mathrm{p}<0.01)$. In marked contrast, the other three groups all showed similarly rapid tumor growth. Considering a survival cutoff criteria, when the aggregate tumour burden $>1 \mathrm{~cm}$ in diameter, the mouse was euthanasia. The survival curve showed that mice in the three control groups

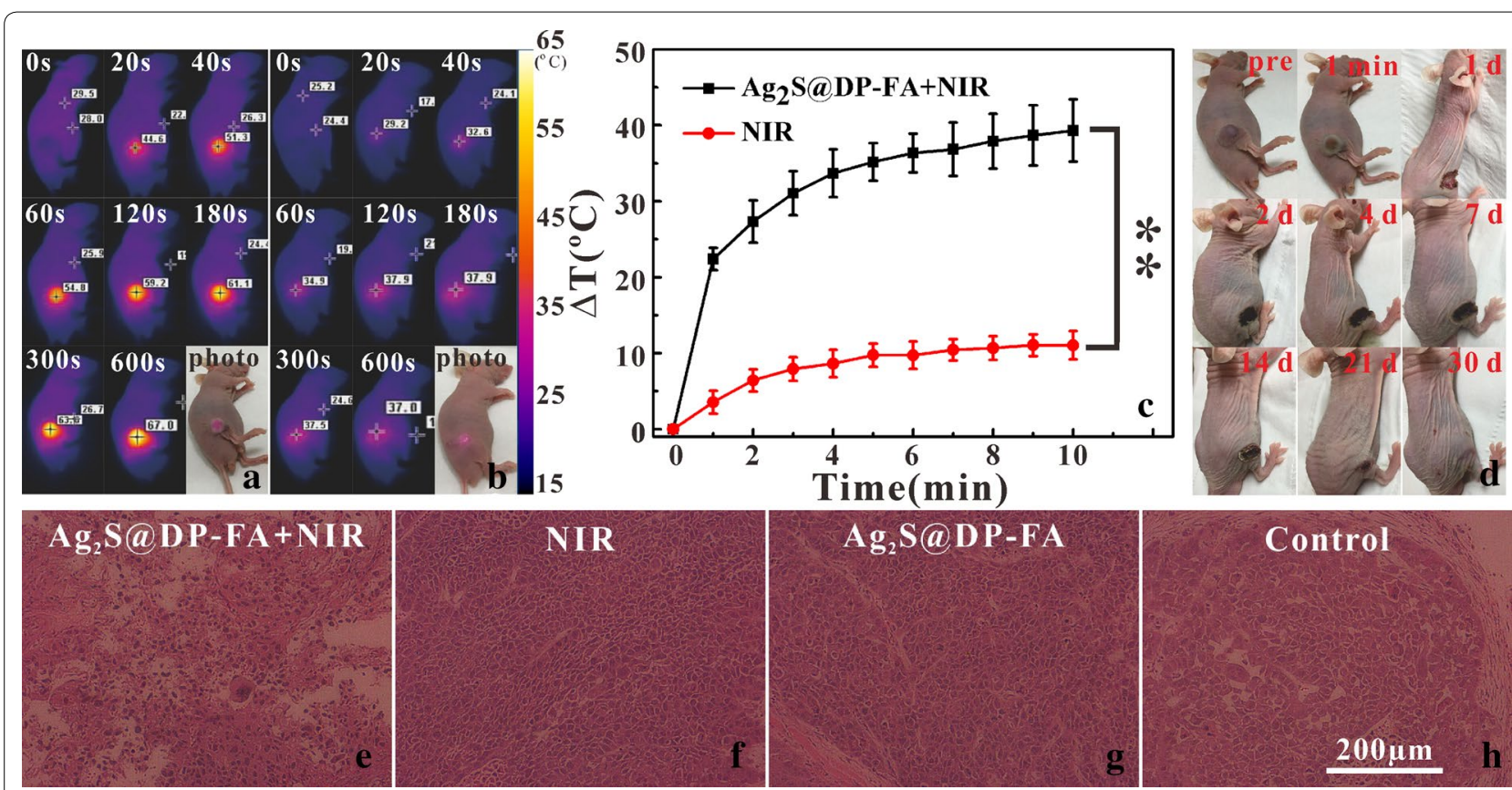

Fig. 13 Infrared thermal images of HeLa tumor-bearing nude mouse tail intravenously injected with $\mathrm{Ag}_{2} \mathrm{~S} @ \mathrm{DP}-\mathrm{FA}(\mathbf{a})$ or saline (b) on different times under $808 \mathrm{~nm}$ laser irradiation; the temperature of tumor evolution curves over time $(\mathbf{c})(n=5)$, ${ }^{*}$ meant great significant difference $(p<0.01)$; representative photos of tumor-bearing nude mouse after treatments over time (d); H\&E stain of tumor tissues from different treatment groups (e-h) 

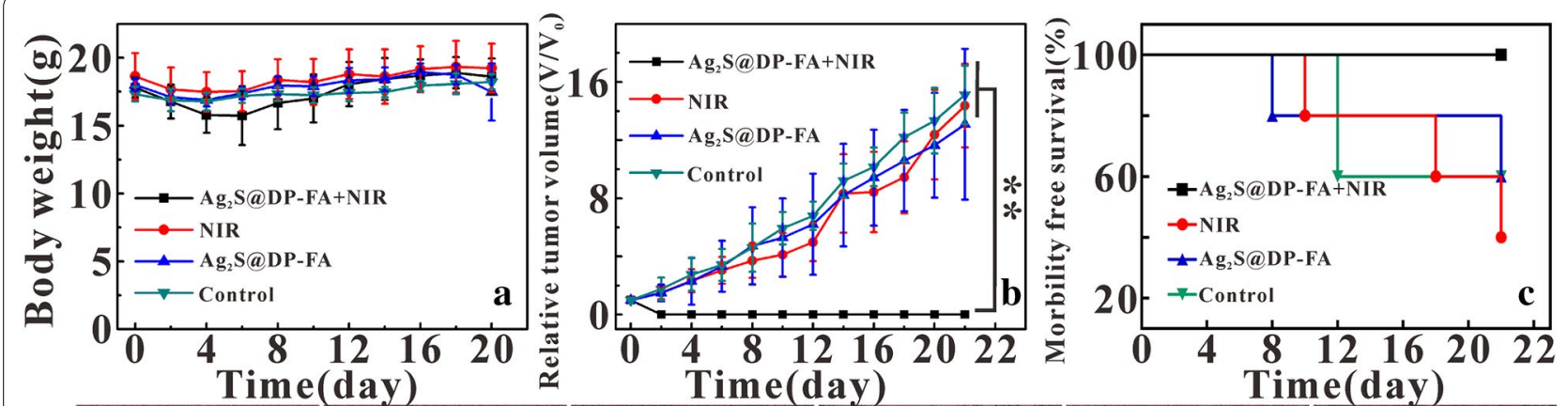

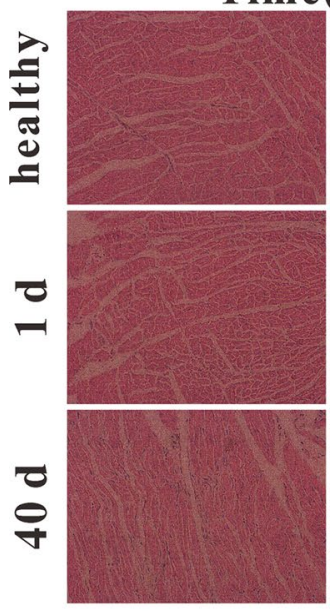

Heart

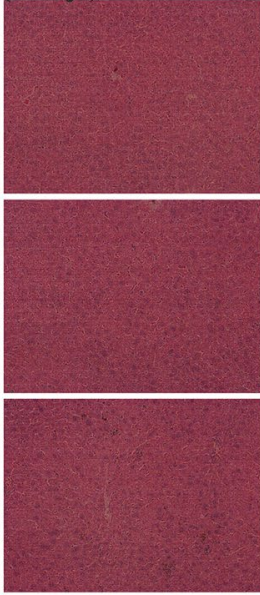

Liver

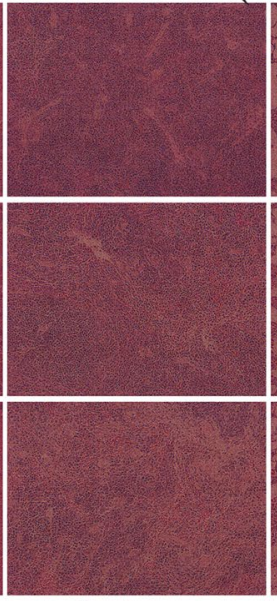

Spleen

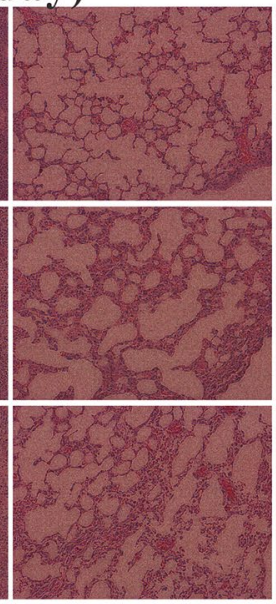

Lung

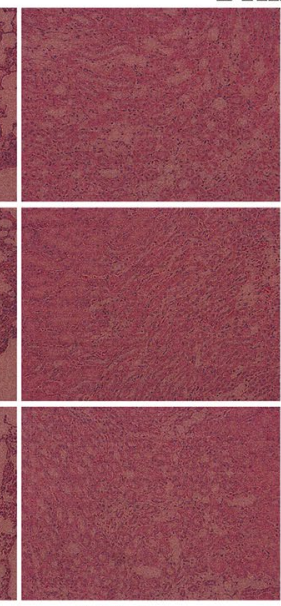

Kidney

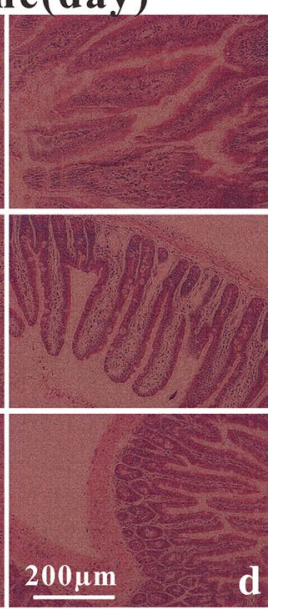

Intestine

Fig. 14 Body weight curves (a), tumor growth curves $(\mathbf{b})$ and survival curve $(\mathbf{c})$ after different treatments $(n=5)$, **meant great significant difference ( $p<0.01$ ); H\&E stained images of major organs from healthy nude mice, 1 and 40 days after Ag 2 @DP-FA and laser irradiation treatment mice, respectively $(\mathbf{d})$

died successively after 8 days, while mice in the treated group were survived over 22 days without a single death (Fig. 14c). Major organs of $\mathrm{Ag}_{2} \mathrm{~S} @ \mathrm{DP}-\mathrm{FA}$ treated mice whose tumors were eliminated by the PTT were collected after 1 and 40 days for histology analysis. No noticeable signal of organ damage and tumor spread were observed from H\&E stained organ slices (Fig. 14d) comparing with healthy nude mice. These works all meant that our therapy was effective without obvious toxicity.

\section{Conclusion}

In this paper, aqueous probe $\mathrm{Ag}_{2} \mathrm{~S} @ \mathrm{DP}-\mathrm{FA}$ with good dispersibility and stability was prepared by coating hydrophobic $\mathrm{Ag}_{2} \mathrm{~S}$ with the mixture of FA modified DP and the other polymers. In vitro and in vivo fluorescence, photoacoustic imaging and photothermal therapy have demonstrated that $\mathrm{Ag}_{2} \mathrm{~S} @ \mathrm{DP}-\mathrm{FA}$ was a safe, integrated diagnosis and treatment probe with multi-mode imaging, photothermal therapy and active targeting ability, which had a great application prospect in the early diagnosis and treatment of tumor.

\section{Additional files}

Additional file 1 Video of in vivo PAl of the nude mouse before tail intravenously injection of $\mathrm{Ag}_{2} \mathrm{~S} @ D P-F A$ under 744 nm laser excitation.

Additional file $\mathbf{2}$ Video of in vivo PAl of same part of tumor on the nude mouse after injection for $12 \mathrm{~h}$ under $744 \mathrm{~nm}$ laser excitation.

Additional file $\mathbf{3}$ Video of in vivo PAl of same part of tumor on the nude mouse under $523 \mathrm{~nm}$ laser excitation.

\section{Abbreviations}

$\mathrm{Ag}_{2}$ S@DP-FA: $\mathrm{Ag}_{2} \mathrm{~S} @ D S P E-\mathrm{PEG}_{2000}-\mathrm{FA}$; FA: folic acid; DP: DSPE-PEG $2000 ; \mathrm{CT}$ : computed tomography; PAl: photoacoustic imaging; MRI: magnetic resonance imaging; PET: positron emission computed tomography; Fl: fluorescence imaging; NIR: near-infrared; PA: photoacoustic; PTT: photothermal therapy; DT: dodecanethiol; FBS: fetal bovine serum; WBC: white blood cell; RBC: red blood cell; HGB: hemoglobin; PLT: platelet; ALT: alanine aminotransferase; AST: aspartate aminotransferase; DMSO: dimethyl sulfoxide; ODE: octadecene; DDC: dicyclohexyl carbodiimide; calcein-AM: calcein acetoxymethyl ester.

\section{Authors' contributions}

$Z X, X Y, Y X, C K, Z R, L C, T F, C Y, A J, H X$ and SX performed experiments and acquisition the date. $Z X, X Y$ and $Y X$ contributed equally to this work and should be considered as co-first authors. ZY designed experiment and give the intellectual input. All authors read and approved the final manuscript. 


\begin{abstract}
Author details
1 Britton Chance Center for Biomedical Photonics at Wuhan National Laboratory for Optoelectronics-Hubei Bioinformatics \& Molecular Imaging Key Laboratory, Department of Biomedical Engineering, College of Life Science and Technology, Huazhong University of Science and Technology, Wuhan 430074, Hubei, People's Republic of China. ${ }^{2}$ Key Laboratory of Optoelectronic Chemical Materials and Devices, Ministry of Education, Jianghan University, Wuhan 430056, People's Republic of China. ${ }^{3}$ Key Laboratory of Biomedical Photonics (HUST), Ministry of Education, Huazhong University of Science and Technology, Wuhan 430074, Hubei, People's Republic of China.
\end{abstract}

\section{Acknowledgements}

The authors gratefully thank the Analytical and Testing Center (HUST) for the help of measurement. I would like to thank Pei Zhang from the Core Facility and Technical Support (Wuhan Institute of Virology) for her help with producing TEM micrographs.

\section{Competing interests}

The authors declare that they have no competing interests.

\section{Availability of data and materials}

All data generated or analyzed during this study are included in this published article and its Additional files 1, 2 and 3.

\section{Consent for publication}

All authors agree to publish this manuscript.

\section{Ethics approval and consent to participate}

All animal experiments were approved by the Animal Experimental Ethics Committee of Huazhong University of Science and Technology.

\section{Funding}

This work was supported by the National Natural Science Foundation of China (Grant Nos. 81471697, 81771878), Yellow Crane Talent (Science \& Technology) Program of Wuhan City and Applied Basic Research Program of Wuhan City (2016060101010044), the Fundamental Research Funds for the Central Universities (Hust, 2016YXMS253, 2017KFXKJC002).

\section{Publisher's Note}

Springer Nature remains neutral with regard to jurisdictional claims in published maps and institutional affiliations.

Received: 12 December 2017 Accepted: 7 April 2018 Published online: 19 April 2018

\section{References}

1. Rosengren A, Wilhelmsen L. Cancer Incidence, Mortality from cancer and survival in men of different occupational classes. Eur J Epidemiol. 2004;19:533-40.

2. Gao S, Chen D, Li Q, Ye J, Jiang H, Amatore C, Wang X. Near-infrared fluorescence imaging of cancer cells and tumors through specific biosynthesis of silver nanoclusters. Sci Rep. 2014;4:4384-9.

3. Plante M, Touhami O, Trinh XB, Renaud MC, Sebastianelli A, Grondin K, Gregoire J. Sentinel node mapping with indocyanine green and endoscopic near-infrared fluorescence imaging in endometrial cancer. A pilot study and review of the literature. Gynecol Oncol. 2015;137:443-7.

4. Tao Z, Dang X, Huang X, Muzumdar MD, Xu ES, Bardhan NM, Song H, Qi R, Yu Y, Li T, Wei W, Wyckoff J, Birrer MJ, Belcher AM, Ghoroghchian PP. Early tumor detection afforded by in vivo imaging of near-infrared II fluorescence. Biomaterials. 2017;34:202-15.

5. Bashkatov AN, Genina EA, Kochubey VI, Tuchin V. Optical properties of human skin, subcutaneous and mucous tissues in the wavelength range from 400 to $2000 \mathrm{~nm}$. J Phys D Appl Phys. 2005;38:2543-55.

6. Aswathy RG, Yoshida Y, Maekawa T, Kumar DS. Near-infrared quantum dots for deep tissue imaging. Anal Bioanal Chem. 2010;397:1417-35.

7. Subila KB, Kishore Kumar G, Shivaprasad SM, George Thomas K. Luminescence properties of CdSe quantum dots: role of crystal structure and surface composition. J Phys Chem Lett. 2013;4:2774-9.
8. Lim YT, Kim S, Nakayama A, Stott NE, Bawendi MG, Frangioni JV. Selection of quantum dot wavelengths for biomedical assays and imaging. Mol Imaging. 2003;2:50-64.

9. Wang LV, Hu S. Photoacoustic tomography: in vivo imaging from organelles to organs. Science. 2012;335:1458-62.

10. Xu M, Wang LV. Photoacoustic imaging in biomedicine. Rev Sci Instrum. 2006;77:041101.

11. Manohar S, Vaartjes SE, van Hespen JC, Klaase JM, van den Engh FM, Steenbergen W, van Leeuwen TG. Initial results of in vivo non-invasive cancer imaging in the human breast using near-infrared photoacoustics. Opt Express. 2007;15:12277-85.

12. Bao C, Conde J, Pan F, Li C, Zhan C, Tian F, Liang S, de la Fuente JM, Cui D. Gold nanoprisms as a hybrid in vivo cancer theranostic platform for in situ photoacoustic imaging, angiography, and localized hyperthermia. Nano Res. 2016;9:1043-56.

13. Du Y, Xu B, Fu T, Cai M, Li F, Zhang Y. Wang Q. Near-infrared photoluminescent $\mathrm{Ag}_{2} \mathrm{~S}$ quantum dots from a single source precursor. J Am Chem Soc. 2010;132:1470-1.

14. Zhu J, Lu Y, Li Y, Jiang J, Cheng L, Liu Z, Guo L, Pan Y, Gu H. Synthesis of $\mathrm{Au}-\mathrm{Fe}_{3} \mathrm{O}_{4}$ heterostructured nanoparticles for in vivo computed tomography and magnetic resonance dual model imaging. Nanoscale. 2014;6:199-202.

15. Liang G, Ye D, Zhang X, Dong F, Chen H, Zhang S, Li J, Shen X, Kong J. One-pot synthesis of $\mathrm{Gd}^{3+}$-functionalized gold nanoclusters for dual model (fluorescence/magnetic resonance) imaging. J Mater Chem. 2013:1:3545-52.

16. Cai W, Chen K, Li ZB, Gambhir SS, Chen X. Dual-function probe for PET and near-infrared fluorescence imaging of tumor vasculature. Med Technol. 2007:48:1862-70.

17. Li K, Liu B. Polymer-encapsulated organic nanoparticles for fluorescence and photoacoustic imaging. Soc Rev. 2014;43:6570-97.

18. Jordan A, Scholz R, Wust P, Fähling H, Felix R. Magnetic fluid hyperthermia (MFH): cancer treatment with AC magnetic field induced excitation of biocompatible superparamagnetic nanoparticles. J Magn Magn Mater. 1999;201:413-9.

19. Conde J, Oliva N, Zhang Y, Artzi N. Local triple-combination therapy results in tumour regression and prevents recurrence in a colon cancer mode. Nat Mater. 2016;15:1128-38.

20. Wang S, Chen Y, Li X, Gao W, Zhang L, Liu J, Zheng Y, Chen H, Shi J. Injectable 2D MoS2-integrated drug delivering implant for highly efficient NIRtriggered synergistic tumor hyperthermia. Adv Mater. 2015;27:7117-22.

21. Bagley AF, Hill S, Rogers GS, Bhatia SN. Plasmonic photothermal heating of intraperitoneal tumors through the use of an implanted near-infrared source. ACS Nano. 2013;7:8089-97.

22. Wust P, Hildebrandt B, Sreenivasa G, Rau B, Gellermann J, Riess H, Felix $\mathrm{R}$, Schlag PM. Hyperthermia in combined treatment of cancer. Lancet Oncol. 2002;3:487-97.

23. Cheng L, He W, Gong H, Wang C, Chen Q, Cheng Z, Liu Z. PEGylated micelle nanoparticles encapsulating a non-fluorescent near-infrared organic dye as a safe and highly-effective photothermal agent for in vivo cancer therapy. Adv Funct Mater. 2013;23:5893-902.

24. Yguerabide J, Yguerabide EE. Light-scattering submicroscopic particles as highly fluorescent analogs and their use as tracer labels in clinical and biological applications: II. Experimental characterization. Anal Biochem. 1998;262:157-76.

25. Gao J, Wu C, Deng D, Wu P, Cai C. Direct synthesis of water-soluble aptamer- $\mathrm{Ag}_{2} \mathrm{~S}$ quantum dots at ambient temperature for specific imaging and photothermal therapy of cancer. Adv Healthc Mater. 2016:5:2437-49.

26. Yang T, Tang Y, Liu L, Lv X, Wang Q, Ke H, Deng Y, Yang H, Yang X, Liu G, Zhao $\mathrm{Y}$, Chen $\mathrm{H}$. Size-dependent $\mathrm{Ag}_{2} \mathrm{~S}$ nanodots for second near-infrared fluorescence/photoacoustics imaging and simultaneous photothermal therapy. ACS Nano. 2017;11:1848-57.

27. Blume G, Cevc G. Liposomes for the sustained drug release in vivo. Biophys Acta. 1990;1029:91-7.

28. You J, Li X, Cui F, Du YZ, Yuan H, Hu F. Folate-conjugated polymer micelles for active targeting to cancer cells: preparation, in vitro evaluation of targeting ability and cytotoxicity. Nanotechnology. 2008;19:045102.

29. Bharali DJ, Lucey DW, Jayakumar H, Pudavar HE, Prasad PN. Folate-receptor-mediated delivery of InP quantum dots for bioimaging using confocal and two-photon microscopy. J Am Chem Soc. 2005;127:11364-71. 
30. Wang K, Wang Q, Luo Q, Yang X. Fluorescence molecular tomography in the second near-infrared window. Opt Express. 2015;23:12669-79.

31. Yang X, Cai X, Maslov K, Wang L, Luo Q. High-resolution photoacoustic microscope for rat brain imaging in vivo. Chin Opt Lett. 2010;8:609-11.

32. Liu Y, Yang X, Gong H, Jiang B, Wang H, Xu G, Deng Y. Assessing the effects of norepinephrine on single cerebral microvessels using opticalresolution photoacoustic microscope. J Biomed Opt. 2013;18:076007.

33. Hong G, Robinson JT, Zhang Y, Diao S, Antaris AL, Wang Q, Dai H. In vivo fluorescence imaging with $\mathrm{Ag}_{2} \mathrm{~S}$ quantum dots in the second near-infrared region. Angew Chem Int Ed. 2012;124:9956-9.

34. Zhang Y, Hong G, Zhang Y, Chen G, Li F, Dai H, Wang Q. $\mathrm{Ag}_{2} \mathrm{~S}$ quantum dot: a bright and biocompatible fluorescent nanoprobe in the second near-infrared window. ACS Nano. 2012;6:3695-702.

35. Gabizon A, Horowitz AT, Goren D, Tzemach D, Mandelbaum-Shavi F, Qazen MM, Zalipsky S. Targeting folate receptor with folate linked to extremities of poly (ethylene glycol)-grafted liposomes: in vitro studies. Bioconjug Chem. 1999;10:289-98.
36. Franken NA, Rodermond HM, Stap J, Haveman J, Van Bre C. Clonogenic assay of cells in vitro. Nat Protoc. 2006;1:2315-9.

37. Lu F, Wu SH, Hung Y, Mou CY. Size effect on cell uptake in well-suspended, uniform mesoporous silica nanoparticles. Small. 2009;5:1408-13.

38. Gerlier D, Thomasset N. Use of MTT colorimetric assay to measure cell activation. J Immunol Methods. 1986;94:57-63.

39. Oh-Hora M, Yamashita M, Hogan PG, Sharma S, Lamperti E, Chung W, Prakriya M, Feske S, Rao A. Dual functions for the endoplasmic reticulum calcium sensors STIM1 and STIM2 in T cell activation and tolerance. Nat Immunol. 2008;9:432-43.

40. Ma Y, Zhang C, Chen X, Jiang H, Pan S, Easteal AJ, Sun X. The influence of modified pluronic F127 copolymers with higher phase transition temperature on arsenic trioxide-releasing properties and toxicity in a subcutaneous model of rats. AAPS PharmSciTech. 2012;13:441-7.
Ready to submit your research? Choose BMC and benefit from:

- fast, convenient online submission

- thorough peer review by experienced researchers in your field

- rapid publication on acceptance

- support for research data, including large and complex data types

- gold Open Access which fosters wider collaboration and increased citations

- maximum visibility for your research: over 100M website views per year

At BMC, research is always in progress.

Learn more biomedcentral.com/submissions 